Results Were included 13 patients, with a mean age of $67 \pm 13.5$ (39-86). The location of tumour was 6 in oral cavity and 7 in oropharynx. The causes of admission was surgery (69.3\%) and complications of neoplastic pathology base (39.7\%); bleeding: $40 \%$, dysphagia: $20 \%$ bronchoaspiration: $20 \%$, oral mycosis: $20 \%$.

According to the nutritional status before admission, were found 4 patients $(30.7 \%)$ with mild malnutrition, $2(15.3 \%)$ with moderately malnutrition, $1(7.7 \%)$ with severe malnutrition and 6 patients with not available data. At discharge: 5 patients (38.5\%) with mild malnutrition, 7 patients with not available data and one patient died during the period.

During the admission period, all the patients received oral feeding, 6 patients received enteral nutrition (EN) by gastrostomy tube. At discharge, $61.5 \%$ of patients received oral diet and the $7.7 \%$ of them needed energy supplementation. The remaining 30.8\% needed to continue with EN.

Conclusions The risk of malnutrition in patients with head and neck cancer is high.

Individualized nutritional support in these patients is necessary to prevent weight loss.

In the absence of parameters to perform an adequate nutritional assessment, we need greater involvement by hospital physicians with the clinical nutrition unit.

No conflict of interest.

\section{CPC-095 OFF-LABEL USE OF ANAKINRA IN A PATIENT WITH FAMILIAL MEDITERRANEAN FEVER: A CASE REPORT}

doi:10.1136/ejhpharm-2013-000276.552

'F Valiente, 'I Sánchez, ${ }^{2}$ A Martínez-Blázquez, 'MA Rodríguez, '1 Ramos. 'Hospital de la Vega Lorenzo Guirao, Pharmacy, Murcia, Spain; ${ }^{2 H o s p i t a l ~ d e ~ l a ~ V e g a ~ L o r e n z o ~ G u i r a o, ~}$ Internal Medicine, Murcia, Spain

Background Familial Mediterranean Fever (FMF) is an autosomal recessive autoinflammatory disease characterised by periodic episodes of fever, peritonitis, arthritis and may be complicated by secondary amyloidosis. FMF affects groups of people from around the Mediterranean Sea. Colchicine is the standard treatment in the prevention of both acute attacks and secondary amyloidosis but there are some resistant patients. Anakinra, an interleukin-1 (IL-1) receptor antagonist indicated for the treatment of the signs and symptoms of rheumatoid arthritis in combination with methotrexate, is also known to affect the severity and the frequency of FMF attacks. Purpose To describe the progress of a patient with FMF treated with anakinra as IL-1 blocker, and evaluate the efficacy and safety of this treatment

Materials and Methods We describe the case of a 53-year-old colchicine-resistant woman suffering from FMF, who was treated with anakinra between April and September 2012 as second-line treatment, after several episodes of recurrent fever and abdominal pain. In order to evaluate the treatment the patient's clinical history and analytical data (C-reactive protein) were reviewed.

Results Anakinra was started with a daily subcutaneous dose (100 mg) associated with oral corticosteroids (methylprednisolone $8 \mathrm{mg}$ ). After the first cycle of treatment, the patient was fine, with no recurrent episodes of fever or abdominal pain. C-reactive protein (CRP) fell from 0.8 to $<0.1 \mathrm{mg} / \mathrm{dl}$. There were no injection site reactions. The only noteworthy adverse effect was neutropenia $(1.4 \times 109 / \mathrm{L})$.Corticosteroids and anakinra doses were reduced to zero and $100 \mathrm{mg}$ every other day respectively.

Conclusions In this case of FMF, anakinra successfully suppressed the number of attacks and the symptoms, without significant adverse reactions and with improvement in quality of life. Controlled trials are necessary to confirm the safety and efficacy of interleukin-1 antagonists in FMF patients.

No conflict of interest.

\section{CPC-096 OPTIMIZATION OF THE TREATMENT OF RHEUMATOID ARTHRITIS WITH BIOLOGICAL TREATMENT}

doi:10.1136/ejhpharm-2013-000276.553

D Ferràndez Martí, A Camacho Calvente, C Campabadal Prat, RM Parés Marimon, R Sala Robinat, J Serrais Benavente, A Perelló Juncà. Hospital Igualada, Pharmacy, Barcelona, Spain

Background The introduction of biological treatment (BT) in the treatment of rheumatoid arthritis (RA) has led to better control of this disease, but on the other hand to a great increase in pharmacy costs.

Purpose To review BT regimens in patients with RA in order to optimise treatment; to try to increase the dosing interval in patients who are responding well and evaluate the savings made.

Materials and Methods Interventional prospective study aiming at optimising the treatment of RA with BT by expanding interval in patients with a good response: adalimumab $40 \mathrm{mg} /$ every 14-21 days and etanercept $50 \mathrm{mg} /$ every 10-14 days. The review of treatments was made jointly between the pharmacy and rheumatology, adjusting the dose and calculating the cost avoided.

Results Patients chosen to extend the dosing interval had a mean DAS28 value of 2.183 (DAS28 $<2.4$ is considered to mean disease remission). By extending the dosing interval $€ 108,049.47$ was saved in a year.

Conclusions The review and optimization of BT dosage regimens in RA patients in remission allowed us to control the disease and save money.

\section{Abstract CPC-096 Table 1}

Rheumatoid arthritis

\begin{tabular}{ll}
\hline Patients with BT & Extended interval \\
\hline Adalimumab: 62 patients & 10 patients $(16.1 \%)$ \\
Etanercept: 53 patients & 5 patients $(9.5 \%)$ \\
\hline
\end{tabular}

Etanercept (cost per unit: 236,805€)

\begin{tabular}{|c|c|c|c|c|}
\hline Posology & $\begin{array}{l}\text { Cost/patient/ } \\
\text { year }\end{array}$ & $\begin{array}{l}\text { Incremental } \\
\text { cost }\end{array}$ & $\begin{array}{l}\text { Number of } \\
\text { patients with } \\
\text { extended interval }\end{array}$ & $\begin{array}{l}\text { Annual } \\
\text { savings }\end{array}$ \\
\hline $\begin{array}{l}\text { Etanercept } 50 \mathrm{mg} / 7 \text { days } \\
\text { (standard) }\end{array}$ & $€ 12,313.86$ & & & \\
\hline Etanercept $50 \mathrm{mg} / 10$ days & $€ 8,524.98$ & $-€ 3,788.88$ & 2 & $€ 7,577.76$ \\
\hline Etanercept $50 \mathrm{mg} / 14$ days & $€ 6,156.93$ & $-€ 6,140.35$ & 3 & $€ 18,470.79$ \\
\hline \multicolumn{5}{|c|}{ Adalimumab (cost per unit: $514,145 €$ ) } \\
\hline Posology & $\begin{array}{l}\text { Cost/patient/ } \\
\text { year }\end{array}$ & $\begin{array}{l}\text { Incremental } \\
\text { cost }\end{array}$ & $\begin{array}{l}\text { Number of } \\
\text { patients with } \\
\text { extended interval }\end{array}$ & $\begin{array}{l}\text { Annual } \\
\text { savings }\end{array}$ \\
\hline $\begin{array}{l}\text { Adalimumab } 40 \text { mg/14 } \\
\text { days (standard) }\end{array}$ & $€ 13,567.77$ & & & \\
\hline $\begin{array}{l}\text { Adalimumab } 40 \text { mg/21 } \\
\text { days }\end{array}$ & $€ 8,946.13$ & $-€ 4,621.64$ & 6 & $€ 27,729.84$ \\
\hline $\begin{array}{l}\text { STOP upon prolonged } \\
\text { remission of the disease }\end{array}$ & $€ 13,567.77$ & $-€ 13,567.77$ & 4 & $€ 54,271.08$ \\
\hline
\end{tabular}

No conflict of interest.

\section{CPC-097 OPTIMIZING CLINICAL PHARMACY: DETERMINING CRITERIA TO TARGET "HIGH RISK" PRESCRIPTIONS}

doi:10.1136/ejhpharm-2013-000276.554

M Philippe, B Leroy, S Coursier, M Bourdelin, H Bontemps. L'hôpital Nord Ouest, Villefranche sur Saône, France

Background Because pharmacists do not yet systematically analyse prescriptions closely due to lack of time and resources, tools to optimise pharmaceutical validation must be developed. 
Purpose To identify pertinent criteria to target high-risk patients or drugs.

Materials and Methods A prospective 3-month study was performed. Daily prescriptions were filtered using an automated computerised system based on selection criteria identified from an analysis of the literature. Pharmaceutical interventions (PIs) that were necessary as a result of the selection criteria and the rest of the prescription were analysed.

Results We analysed 1122 prescriptions, corresponding to 456 patients (mean age 79 years). Prescriptions were grouped together according to several selection criteria: creatininemia $\geq 125 \mu \mathrm{mol} / 1$ (62.1\%), dyskalaemia (23.2\% including 55\% hyperkalaemia and $45 \%$ hypokalaemia), INR $\geq 4(7.2 \%)$ and drug dosages (7.5\% including $37 \%$ vancomycin, $22 \%$ digoxin and $15 \%$ gentamicin). Among the prescriptions selected for creatininemia $\geq 125 \mu \mathrm{mol} / 1,45.7 \%$ were associated with severe kidney failure and $26.4 \%$ with moderate kidney failure.

The rate of PIs was $16 \%(\mathrm{n}=179)$ and varied according to the criteria: $22 \%$ and $19.6 \%$ respectively for severe and moderate kidney failure, $33.3 \%$ for hyperkalaemia, $10.3 \%$ for hypokalaemia, $13.8 \%$, for INR, $4.4 \%$ for drug dosages.

The PI was related to the selection criteria in $77 \%$ of the cases. The rate of acceptance by prescribers was $80.6 \%$.

Conclusions Carefully choosing pertinent criteria to philtre prescriptions seems to be an interesting option to optimise our approach to clinical pharmacy.

Our study shows that criteria associated with kidney failure and hyperkalaemia seem to be pertinent as they are related to numerous PIs. Following up INR $>4$ should also be added as a pertinent criterion, as anticoagulants are often the cause of iatrogenic events.

This type of selection could be used to perform a transversal analysis of prescriptions, without discrimination by hospital unit.

No conflict of interest.

\section{CPC-098 OSTEOPOROSIS AFTER LUNG TRANSPLANT}

doi:10.1136/ejhpharm-2013-000276.555

'P Ging, ${ }^{2} \mathrm{~L}$ Lawrie, ${ }^{2} \mathrm{~S}$ Winward, ${ }^{2} \mathrm{JJ}$ Egan, ${ }^{1} \mathrm{C}$ Meegan. ${ }^{1}$ Mater Misericordiae University Hospital, Pharmacy, Dublin, Ireland (Rep.); 'Mater Misericordiae University Hospital, National Heart and Lung Transplant Unit, Dublin, Ireland (Rep.)

Background Osteoporosis after a lung transplant is common, with reported vertebral fracture rates of up to $30 \%$ [1]. Bisphosphonates, and calcium and vitamin D supplements may be less effective in patients who remain on steroid treatment [2]. Corticosteroids are more detrimental to spinal bone mineral density than to the hip [2]; however risk prediction systems use hip T-scores to predict risk and make treatment recommendations [3, 4].

We reviewed the prophylaxis of osteoporosis in a cohort of patients at the time of listing and up to 6 years post-transplant.

Purpose We wished to identify:

1. any potential for improvement in prescribing

2. risk factors for clinically significant lumbar fractures

3. the utility of currently available osteoporosis risk algorithms in this cohort.

Materials and Methods We conducted a retrospective chart review $(\mathrm{n}=27)$.

Patients' risk of fracture at the time of listing for transplant was calculated using three different methods including WHO charts and American College of Rheumatology algorithm for steroid-treated patients.

We attempted to create a model to predict fracture in transplant recipients using known risk factors.

Results At time of listing, all patients were taking at least $5 \mathrm{mg}$ of prednisolone daily plus a bisphosphonate and appropriate calcium and vitamin D supplementation. Many already had osteoporotic $\mathrm{T}$ scores at this point. Fracture rates in our cohort are in line with published data, but substantially higher than those predicted from algorithms. Improvised algorithms using lumbar $T$ scores were better at predicting risk than published methods. The only risk factor in our cohort that predicted subsequent fracture was lumbar spine T-score (Mean -1.2 versus -2.65 in the fracture group $(\mathrm{P}=0.009)$ ).

Conclusions Current algorithms underestimate risk, new charts should be created using lumbar T-scores. Our results emphasise that current prophylaxis strategies are not successful in preventing fractures in those who have osteoporosis and remain on prednisolone. Early osteoporosis prophylaxis and alternative treatments are essential to prevent fractures.

\section{References}

1. Cohen A, Shane E, (2003). Osteoporosis after solid organ and bone marrow transplantation. Osteoporos Int 14, 617-30.

2. Weinstein RS, (2011). Glucocorticoid-Induced Bone Disease. N Engl $\mathrm{J}$ Med 365, 62-70.

3. World Health Organization Collaborating Centre for Metabolic Bone Diseases, University of Sheffield, UK. Online risk prediction tool. http://www.shef.ac.uk/FRAX/tool.jsp?country=1 (accessed 3 Nov 2011).

4. Grossman JM, et al, (2010). American College of Rheumatology 2010 recommendations for the prevention and treatment of glucocorticoid-induced osteoporosis. Arthritis Care Res 62, 1515-26.

No conflict of interest.

\section{CPC-099 PATIENTS ON VITAMIN K ANTAGONISTS (THE BENEFIT OF PHARMACY STUDENTS EDUCATING VKA PATIENTS IN AN UNIVERSITY HOSPITAL)}

doi:10.1136/ejhpharm-2013-000276.556

${ }^{1} \mathrm{C}$ Breuil, ${ }^{1} \mathrm{M}$ Baudon-Lecame, ${ }^{1} \mathrm{C}$ Hecquard, ${ }^{2} \mathrm{C}$ Le Hello, ${ }^{2} \mathrm{~A}$ Lequerrec, ${ }^{3} \mathrm{G}$ Zalcman, ${ }^{3}$ E Bergot. ${ }^{1} \mathrm{CHU}$ DE CAEN, Pharmacy, Caen, France; ${ }^{2} \mathrm{CHU}$ DE CAEN, HaemostasisCoagulation, Caen, France; ${ }^{3} \mathrm{CHU}$ DE CAEN, pneumology, Caen, France

Background Vitamin K Antagonists are the most used anticoagulants in the treatment of thrombotic diseases and their misuse is an important source of medicines-related illness.

Purpose To study the effect of targeted information on patients' knowledge of their VKA treatment.

Materials and Methods The study took place between 05/07/2012 and 09/07/2012 as described below: An assessment grid including 18 questions grouped in 4 items was made by pharmacists and checked by the 'haemostasis-coagulation' group. It included a) general knowledge, b) meaning of the INR test, c) drug and food interactions and d) signs of bleeding. The students were trained (by pharmacists) and empowered (by specialist members of the 'haemostasis-coagulation' group) The pharmacy students evaluated patient knowledge with the grid (T0) The answers were analysed in order to highlight points where knowledge was lacking Targeted therapeutic information was supplied on the deficient points Patients were re-evaluated with the same grid before discharge (T1).

Results 73 patients (27 males/46 females) were evaluated and received therapeutic information. The mean age was 66 years. $57 \%$ of responses were adequate with $69 \%, 55 \%, 37 \%$ and $47 \%$ of correct answers for items a, b, c and d respectively. 41 (56\%) of the 73 patients were re-evaluated before discharge. In this group of patients, $50 \%$ answers were correct initially and $78 \%$ after education. An improvement of the knowledge was observed for all items with $73 \%$ vs. $32 \%, 66 \%$ vs. $30 \%, 83 \%$ vs. $18 \%$ and $72 \%$ vs. $27 \%$ of correct answers at T1 vs. T0 for items a, b, c and d, respectively.

Conclusions The improvement in patients' knowledge of their VKA treatment shows the benefit of this approach based on the patients being educated by empowered pharmacy students. That's why this process should be extended to other units with VKA patients.

\section{Reference}

1. VKA, therapeutic information, patients' knowledge.

No conflict of interest. 